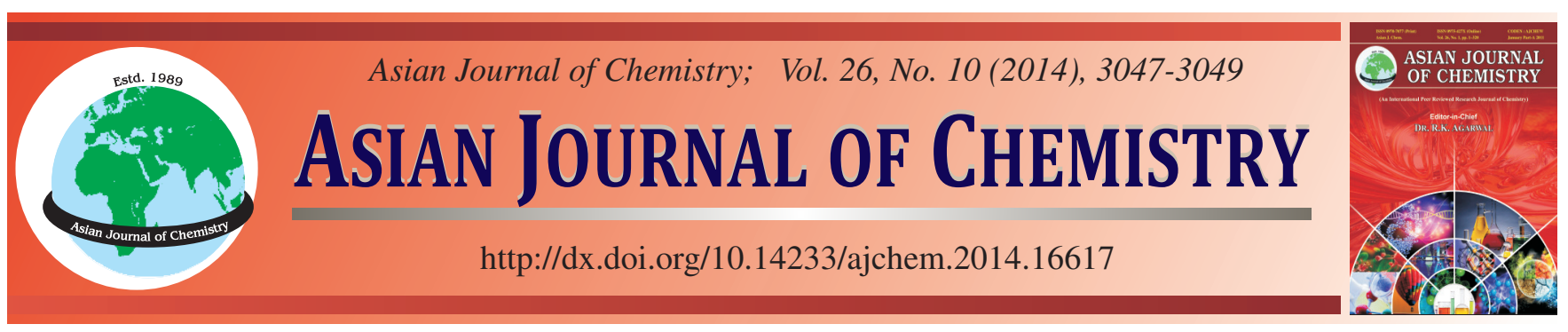

\title{
Kinetics for Synthesis of 1-Octanethiol
}

Guogin Hu*, Peiei Wu, Liuyang Tan and Leiming CuI

School of Chemical Engineering and Energy, Zhengzhou University, Zhengzhou, Henan Province, P.R. China

*Corresponding author: Tel./Fax: +86 371 67781712; E-mail: huguoqin@zzu.edu.cn

The reaction kinetics of synthesis of 1 -octanethiol from the sodium hydrosulfide and $n$-octyl bromide using tetrabutyl ammonium bromide as the phase transfer catalyst was studied. The reaction kinetic model was established. Through the experimental verification, the reaction kinetics can be described by first order reaction kinetics as: $\mathrm{r}_{\mathrm{A}}=-\mathrm{dc}_{\mathrm{A}} / \mathrm{dt}=7.97973 \times 10^{7} \exp (-7073.9 / \mathrm{T}) \mathrm{c}_{\mathrm{A}}$. The apparent activation energy of the reaction was $58.815 \mathrm{KJ} \mathrm{mol}^{-1}$. The calculated results using the kinetics parameters from the kinetic model agree well with the experimental data.

Keywords: 1-Octanethiol, Sodium hydrosulfide, $n$-Octyl bromide, Reaction kinetics.

\section{INTRODUCTION}

1-Octanethiol is mainly used for synthesizing the polymerization regulator and vulcanization modifier in the production of synthetic rubber, as well as the organic synthesis intermediates in medicines, dyes, pesticides, etc. ${ }^{1-6}$. In recent years, it has been used mostly for the preparation of the antioxidants and the catalysts, such as the preparation of antioxidants565 , platinum and other precious metals catalyst ${ }^{7}$. Moreover, 1-octanethiol can also carry out on the chemical adsorption in heavy metals' surface, forming self-assembed monolayers and can be used as the hardening agent on the metal's surface, organic additives, modifiers, metal corrosion inhibitors, etc. ${ }^{8-10}$. With the development of its downstream products, the demand of 1-octanethiol is increasing. However, by far, there haven't many domestic companies to produce the 1-octanethiol. So, starting from the practical industrial application, we used the $n$-octyl bromide and the sodium hydrosulfide which is of industrial grade with $70 \%$ as the main raw material to synthesize 1-octanethiol, aiming at the development of domestic market. We carried out the research on the kinetics of the synthesis of 1-octanethiol and the results of this study could provide a theoretical basis for the process conditions of the synthesis of 1 -octanethiol. The reaction of $n$-octyl bromide and the sodium hydrosulfide is the substitution reaction and the reaction principle can be expressed as follows:

$$
\mathrm{C}_{8} \mathrm{H}_{17} \mathrm{Br}(\mathrm{A})+\mathrm{NaHS}(\mathrm{B}) \stackrel{\text { твAB }}{\longrightarrow} \mathrm{C}_{8} \mathrm{H}_{17} \mathrm{SH}(\mathrm{C})+\mathrm{NaBr}(\mathrm{D})
$$

The kinetic equation for the gneration of 1-octanethiol is as follows:

$$
\mathrm{r}_{\mathrm{A}}=-\mathrm{dc}_{\mathrm{A}} / \mathrm{dt}=\mathrm{kc}_{\mathrm{A}}{ }^{\mathrm{a}} \mathrm{c}_{\mathrm{B}}{ }^{\mathrm{b}}
$$

If the concentration of NaHS did not change in the reaction, then the kinetic equations can be simplified as:

$$
\mathrm{r}_{\mathrm{A}}=-\mathrm{dc}_{\mathrm{A}} / \mathrm{dt}=\mathrm{kc}_{\mathrm{A}}^{\mathrm{a}}
$$

Assuming $\mathrm{a}=1$, then the reaction kinetics can be described by first order reaction kinetics as:

$$
\mathrm{kt}=-\ln \left(\mathrm{c}_{\mathrm{A}} / \mathrm{c}_{\mathrm{A} 0}\right)=-\ln \left(1-\mathrm{x}_{\mathrm{A}}\right)
$$

According to this assumption, the experiment was performed at different temperature to determine the relationship between the concentration of $n$-octyl bromide and time.

\section{EXPERIMENTAL}

In all experiments, distilled water was used. Sodium hydrosulfide and $n$-octyl bromide were supplied by Sanmenxia Aoke Chemical Industry Co., Ltd. Tetrabutylammonium bromide was supplied by Tianjin Kermel Chemical Reagent Co. and were of AR grade with purity higher than $99.5 \%$.

GC spectra were measured by GC-9800TFP. All the matters used were weighed by an electronic balance (Mettler Toledo AB204-N) with an accuracy of $\pm 0.0001 \mathrm{~g}$.

General procedure: Quantitative aqueous solution of sodium hydrosulfide was added into the three-necked flask. The quality of the tetrabutylammonium bromide catalyst was $1 \%$ of $n$-octyl bromide. The system should be heated up rapidly 
TABLE-1

$\mathrm{c}_{\mathrm{A}} / \mathrm{c}_{\mathrm{A} 0}$ AT DIFFERENT TEMPERATURE AND TIME

\begin{tabular}{|c|c|c|c|c|c|c|c|c|c|}
\hline \multirow{2}{*}{ Temp. (K) } & \multicolumn{9}{|c|}{ Time $(\min )$} \\
\hline & 15 & 30 & 45 & 60 & 75 & 90 & 105 & 120 & 135 \\
\hline 298.15 & 83.29 & 81.78 & 78.72 & 76.74 & 73.98 & 72.38 & 69.41 & 63.57 & 62.82 \\
\hline 308.15 & 46.62 & 37.70 & 29.12 & 25.02 & 21.46 & 17.62 & 14.58 & 12.31 & 10.00 \\
\hline 318.15 & 43.72 & 31.76 & 20.96 & 11.08 & 7.99 & 5.11 & 3.56 & 3.38 & 2.08 \\
\hline 328.15 & 40.29 & 25.49 & 16.21 & 9.80 & 6.50 & 4.49 & 2.59 & 1.68 & 0.90 \\
\hline 338.15 & 27.88 & 19.22 & 9.01 & 3.54 & 1.22 & 0.61 & - & - & - \\
\hline
\end{tabular}

to the setting temperature after $n$-octyl bromide was slowly added dropwise at room temperature. And the temperature should be controlled in $\pm 0.5^{\circ} \mathrm{C}$ in the range of specified temperature. Samples were taken every $15 \mathrm{~min}$ and were analyzed using gas chromatography when the reaction solution reached the setting temperature. Each time, $1 \mathrm{~mL}$ of sample was taken.

\section{RESULTS AND DISCUSSION}

Exclusion of the impact of internal and external diffusion and volume changes: To determine the intrinsic kinetics of reaction, the interference of internal and external diffusion must be eliminated firstly. Internal diffusion resistance is encountered when the reactants penetrating into the catalyst's internal. In order to investigate the phase transfer catalyst's effect on the internal diffusion, we conducted experiments with different content of catalyst and we discovered when the catalyst's content is lower than $2 \%$, the conversion rate of $n$ octyl bromide didn't increase with the increase of the content of catalyst. So in order to eliminate the internal diffusion, the catalyst's content was $1 \%$. And we discovered that when the stirring rate was more than $400 \mathrm{r} / \mathrm{min}$, the effect of external diffusion could be eliminated. In addition, sampling $1 \mathrm{~mL}$ each time can ignore the effect of changes of the volume of the reaction solution ${ }^{11-13}$.

Determination of kinetics equation: In this experiment, the $n$-octyl bromide was added dropwise into the reaction system, so the concentration of the $n$-octyl bromide in the reaction system was very small, then its concentration can be considered essentially unchanged and the reaction system can be thought of as the homogeneous reaction system. The experimental results at different temperature is listed in Table-1, Fig. 1 describes the relationship between the concentration of $n$-octyl bromide and reaction time at different temperature, Fig. 2 shows the relationship between the reaction time $t$ and $\ln \left(\mathrm{c}_{\mathrm{A}} / \mathrm{c}_{\mathrm{A} 0}\right)$, the linear regression equations is given in Table- 2 . According to the data, the assumption that the reaction is the first order reaction is correct.

Determination of reaction apparent activation energy: In order to investigate the influence of temperature on the kinetics equation, we calculated the value of the apparent

\begin{tabular}{ccc}
\multicolumn{2}{c}{ TABLE-2 } \\
& LINEAR REGRESSION EQUATIONS \\
\hline Temp. $(\mathrm{K})$ & Regression equations & Correlation coefficient \\
\hline 298.15 & $\mathrm{y}=-0.00233 \mathrm{x}+4.472$ & 0.9826 \\
308.15 & $\mathrm{y}=-0.0125 \mathrm{x}+3.992$ & 0.9971 \\
318.15 & $\mathrm{y}=-0.0258 \mathrm{x}+4.117$ & 0.9832 \\
328.15 & $\mathrm{y}=-0.0302 \mathrm{x}+4.141$ & 0.999 \\
338.15 & $\mathrm{y}=-0.0539 \mathrm{x}+4.409$ & 0.9841 \\
\hline
\end{tabular}

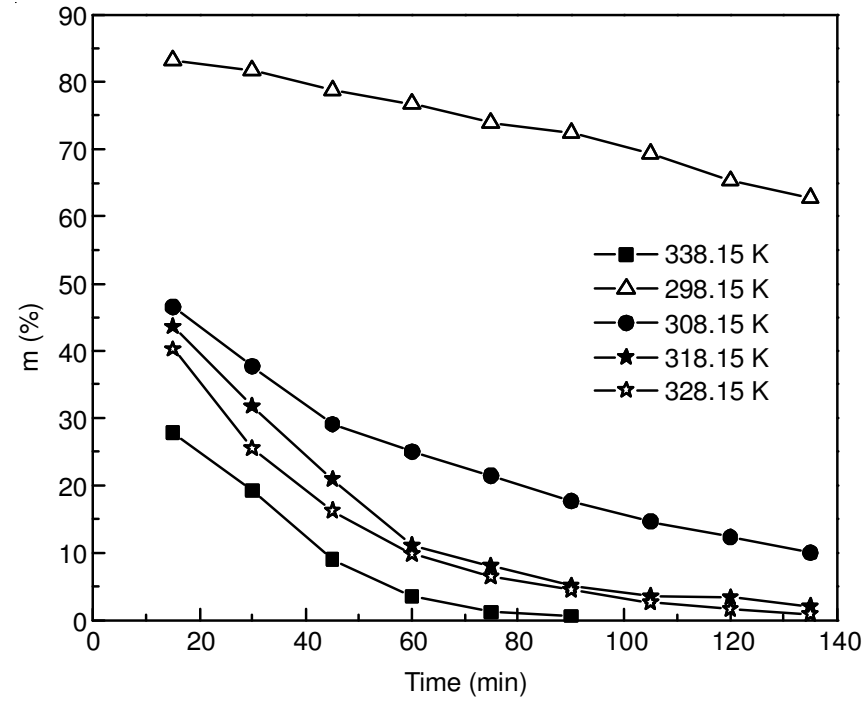

Fig. 1. Relationship between $\mathrm{c}_{\mathrm{A}} / \mathrm{c}_{\mathrm{A} 0}$ and $\mathrm{t}$

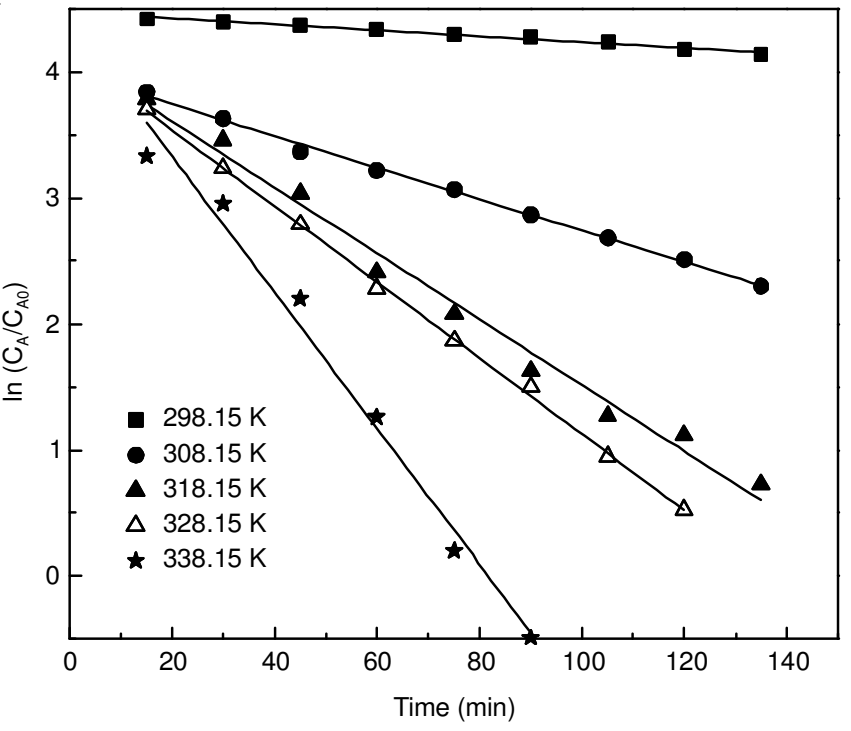

Fig. 2. Relationship between $\ln \left(\mathrm{c}_{\mathrm{A}} / \mathrm{c}_{\mathrm{A} 0}\right)$ and $\mathrm{t}$

reaction rate constant $\mathrm{K}$ at different temperature according to the corresponding measurements of the concentration of $n$-octyl bromide at different time and the kinetic parameters derived by the regression of the relationship between $\ln \left(\mathrm{c}_{\mathrm{A}} / \mathrm{c}_{\mathrm{A} 0}\right)$ and $\mathrm{t}$, which was shown in Table-3. Fig. 3 describes the effect of temperature on reaction ratio constant. Fig. 3 showed that there was a good linear relationship between $\ln \mathrm{K}$ and $\mathrm{T}^{-1}$.

According to the Arrhenius equation:

$$
\ln \mathrm{k}=\frac{-\mathrm{E}_{\mathrm{a}}}{\mathrm{RT}}+\ln \mathrm{k}_{0}
$$


we plotted a straight line of $\ln \mathrm{k}$ versus $\mathrm{T}^{-1}$. And according to the linear regression from Fig. 3, Eqn. (1) can be rewritten as follows:

$$
\ln \mathrm{k}=\frac{-7073.9}{\mathrm{~T}}+\ln \mathrm{k}_{0}
$$

According to the slope of the line and the intercept of the line, we calculated the apparent activation energy and preexponential factor of the arrhenius equation as follows:

$\mathrm{E}_{\mathrm{a}}=7073.9 \times 8.3145=58815.94155 \mathrm{~J} / \mathrm{mol}$

$$
\mathrm{k}_{0}=\mathrm{e}^{18.195}=7.97973 \times 10^{7}
$$

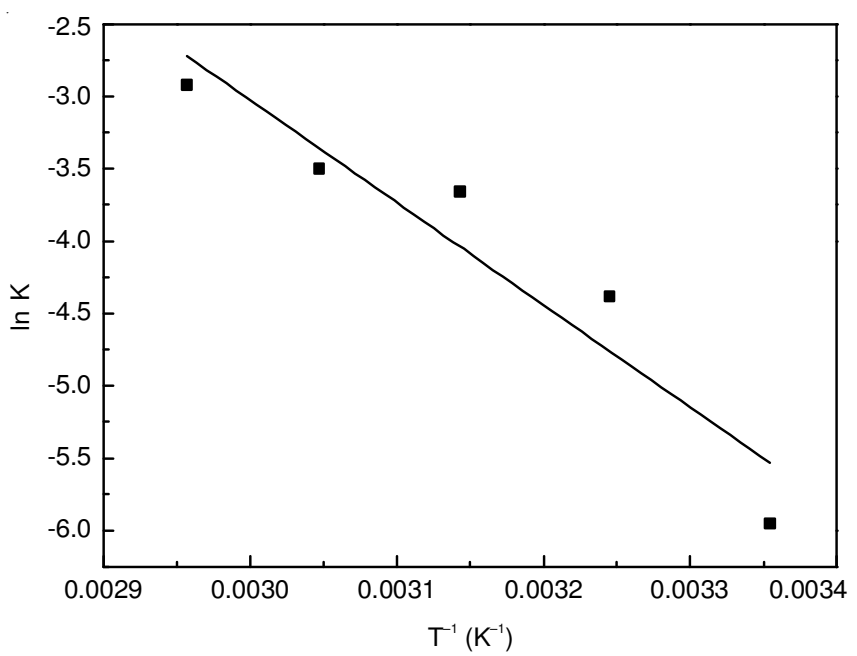

Fig. 3. Effect of temperature on reaction ratio constant

\section{TABLE-3}

RELATIONSHIP BETWEEN THE REACTION RATIO CONSTANT $\mathrm{k}$ AND TEMPERATURE T

\begin{tabular}{cccc}
\hline Temp. $(\mathrm{K})$ & $1 / \mathrm{T}$ & $\mathrm{k}\left(\mathrm{min}^{-1}\right)$ & $\ln \mathrm{k}$ \\
\hline 298.15 & 0.00335 & 0.00233 & -6.062 \\
308.15 & 0.00325 & 0.0125 & -4.382 \\
318.15 & 0.00314 & 0.0258 & -3.657 \\
328.15 & 0.00305 & 0.0302 & -3.500 \\
338.15 & 0.00296 & 0.0539 & -2.921 \\
\hline
\end{tabular}

Validation of the kinetic equation: Based on the above analysis, the apparent kinetic equation can be expressed as follows:

$$
\mathrm{r}_{\mathrm{A}}=-\mathrm{dc}_{\mathrm{A}} / \mathrm{dt}=7.97973 \times 10^{7} \exp (-7073.9 / \mathrm{T}) \mathrm{c}_{\mathrm{A}}
$$

The integral formula is as follows:

$$
\mathrm{kt}=-\ln \left(\mathrm{c}_{\mathrm{A}} / \mathrm{c}_{\mathrm{A} 0}\right) \quad \text { or } \quad \mathrm{c}_{\mathrm{A}}=\mathrm{c}_{\mathrm{A} 0} \exp (-\mathrm{kt})
$$

Specially, the reaction ratio constant:

$$
\mathrm{r}_{\mathrm{A}}=-\mathrm{dc}_{\mathrm{A}} / \mathrm{dt}=7.97973 \times 10^{7} \exp (-7073.9 / \mathrm{T}) \mathrm{c}_{\mathrm{A}}
$$

In order to investigate the credibility of the kinetic equation, we calculated the concentration of $n$-octyl bromide $\left(\mathrm{c}_{\mathrm{A}} / \mathrm{c}_{\mathrm{A} 0 \text {, cal }}\right)$ at $323.15 \mathrm{~K}$ using the integral formula at different reaction time. The calculated concentration $\left(\mathrm{c}_{\mathrm{A}} / \mathrm{c}_{\mathrm{A} 0 \text {,cal }}\right)$ and the experimental concentration $\left(\mathrm{c}_{\mathrm{A}} / \mathrm{c}_{\mathrm{A} 0 \text {, exp }}\right)$ of $n$-octyl bromide is listed in Table-4. Through the comparison, we discovered the prediction results are satisfactory.

\begin{tabular}{ccccc}
\multicolumn{5}{c}{ TABLE-4 } \\
\multicolumn{5}{c}{$\begin{array}{c}\text { EXPERIMENTAL CONCENTRATION COMPARED } \\
\text { WITH THE CALCULATED } \mathrm{c}_{\mathrm{A}} / \mathrm{c}_{\mathrm{A} 0} \mathrm{AT} 323.15 \mathrm{~K}\end{array}$} \\
\hline \multirow{2}{*}{ Entry } & $\mathrm{t} / \mathrm{min}$ & $\mathrm{c}_{\mathrm{A}} / \mathrm{c}_{\mathrm{A} 0, \mathrm{cal}}$ & $\mathrm{c}_{\mathrm{A}} / \mathrm{c}_{\mathrm{A} 0, \exp }$ & $\frac{\mathrm{c}_{\mathrm{A}} / \mathrm{c}_{\mathrm{A} 0, \exp }-\mathrm{c}_{\mathrm{A}} / \mathrm{c}_{\mathrm{A} 0, \mathrm{cal}}}{\mathrm{c}_{\mathrm{A}} / \mathrm{c}_{\mathrm{A} 0 \text { exp }}} \times 100$ \\
\hline 1 & 15 & 68.90 & 68.02 & -1.29 \\
2 & 30 & 47.47 & 47.52 & 0.11 \\
3 & 45 & 32.71 & 33.64 & 2.76 \\
4 & 60 & 22.53 & 23.57 & 4.41 \\
5 & 75 & 15.53 & 15.36 & -1.11 \\
6 & 90 & 10.70 & 10.88 & 1.65 \\
7 & 105 & 7.37 & 7.39 & 0.27 \\
8 & 120 & 5.08 & 4.86 & -4.53 \\
9 & 135 & 3.50 & 3.67 & 3.27 \\
\hline
\end{tabular}

\section{Conclusion}

The reaction of $n$-octyl bromide and sodium hydrosulfide is similar to the first order reaction when the stirring rate was more than $400 \mathrm{rpm}$ and the concentration of the sodium hydrosulfide is excess. And the reaction speed is related to the concentration of $n$-octyl bromide and temperature.

The chemical reaction kinetics equation of synthesis of 1 -octanethiol from the sodium hydrosulfide and $n$-octyl bromide using tetrabutyl ammonium bromide as the phase transfer catalyst can be expressed as:

$$
\mathrm{r}_{\mathrm{A}}=-\mathrm{dc}_{\mathrm{A}} / \mathrm{dt}=7.97973 \times 10^{7} \exp (-7073.9 / \mathrm{T}) \mathrm{c}_{\mathrm{A}}
$$

When the temperature was among the range of 298.15$338.15 \mathrm{~K}$, the apparent activation energy of the reaction is $58815.94155 \mathrm{KJ} / \mathrm{mol}$, which among the range of general chemical reaction activation energy of $40-400 \mathrm{KJ}$, so the reaction belong to the chemical reaction control process.

\section{REFERENCES}

1. H.Y. Tang, Y.D. Zhang and Z.X. Wang, Speciality Petrochem., 27, 23 (2010).

2. J.S. Zhang, J.X. Xiao, Z.Y. Liu, J.G. Qiu, Z.X. Liu and Z. Zhang, Organo-Fluorine Ind., 1, 54 (2007).

3. L. Ma, M.H. Zhang and L.J. Jiang, J. Sci. China Ser. B, 12, 1248 (1992).

4. K. Schoumacker, M. Cattenot, C. Geantet, E. Puzenat, M. Lacroix and J.M. Herrmann, Catal. Commun., 11, 1116 (2010).

5. T.L. Cairns, A.W. Larchar and B.C. Mckusick, Org. Chem., 18, 748 (1953).

6. C.S. Marvel and C.D. Lewis, J. Polym. Sci.., 3, 354 (1948).

7. Q. Zhou, Y. Ling and C. Yao, Chem. World, 2, 107 (2007).

8. S. Matsunaga, R. Yokomori, D. Ino, T. Yamada, M. Kawai and T. Kobayshi, Electrochem. Commun., 9, 645 (2007).

9. M.L. Foresti, F. Loglio, M. Innocenti, S. Bellassai, F. Carlà, E. Lastraioli, G. Pezzatini, C. Bianchini and F. Vizza, Langmuir, 26, 1802 (2010).

10. L. Pan, K. Tahara, T. Masuko and Y. Hisaeda, Inorg. Chim. Acta, 368, 194 (2011).

11. Z. Zhang and H. Li, Chem. Reagents, 31, 292 (2009).

12. A. Marafi, E. Kam and A. Stanislaus, Fuel, 87, 2131 (2008).

13. W.C. Chan and Y.Z. Lai, Bioresour. Technol., 99, 4380 (2008). 